Jurnal Ilmu Sosial dan Pendidikan (JISIP)

Vol. 5 No. 3 Juli 2021

Terakreditasi Peringkat 5 (No. SK: 85/M/KPT/2020)

e-ISSN : 2656-6753, p-ISSN: 2598-9944

DOI: 10.36312/jisip.v5i3.2082/http://ejournal.mandalanursa.org/index.php/JISIP/index

\title{
Pengaruh Pendidikan Kesehatan Keluarga Terhadap Kepatuhan Diet Penderita Diabetes Mellitus Tipe 2 Di Puskesmas Masbagik Lombok Timur
}

\author{
Nurul Ilmi ${ }^{1)}$ Hadi Suryatno ${ }^{2)}$, Surniati ${ }^{3)}$ \\ ${ }^{1,2,3)}$ Prodi S1 Keperawatan Sekolah Tinggi Ilmu Kesehatan (STIKES) Mataram \\ Email Korespondensi: nurulilmisukses@gmail.com
}

\section{Article Info \\ Article history:}

Article Accepted: June 062021

Publication : July 042021

Keywords:

Family Health Education

(Counseling), Dietary

Compliance, Patients With

Type 2 Diabetes Mellitus

\section{Article Info}

Article history:

Received: May 172021

Revised : May 202021

Accepted: June 062021

Keywords:

Pendidikan Kesehatan

Keluarga (Penyuluhan),

Kepatuhan Diet, Penderita

Diabetes Mellitus Tipe 2

\begin{abstract}
Diabetes Mellitus risk to people who frequently eat foods that contain toomuch sugar or sweeteners. When blood sugar levelsclose to normaly etit must be because the diet the rapycanhel preduce blood glucose level sbebetter toprevent the onset of complications in Diabetes Mellitus. The design used in this study are preexperimental design with a design or design one-group pre-test-post-test design (prepost in one group). The population of all patients with type 2 diabetes mellitus in the village health center Masbagek Work Area North East Lombok Masbagek 25 people. Samples saturated with engineering samples (total sampling). The instruments used were interviews and observation. observation using a 24-hour Food Recall Form. Analysis of the data in this study using a statistical test $t$-test with a significance level of $0.05 \%$. Based on calculations using thet-test analysis using the pre-post test one group design canbe obtainedt countthe number of respondents 6 of 25 people obtained $D F=N-1=24$. Degrees of freedomis worth 24 on thet-table with a significance level of 0.05 is worth 2.064 sot count>t-table (6>2.064), this shows no effect of family health education (counseling) to the level of dietary adherence was higher inrespond ersafter follow the family health education (counseling) compared with the priorgiven family health education (counseling) in the village of North Masbagik Working Area health Center East Lombok. There is the influence of family health education (counseling) to dietary adherence in patients with type 2 diabetes mellitus in which the value of $t$ count $>t$ table $=6>2.064$. With the provision of family health education (counseling) can be used as an input of knowledge about diet in patients with type 2 diabetes mellitus as recommended diet.
\end{abstract}

\section{Abstrak}

Diabetes Mellitus beresiko terhadap orang yang sering mengkonsumsi makanan yang mengandung gula atau pemanis terlalu berlebihan. Apabila kadar gula darah belum mendekati normal maka harus melakukan terapi diet karena dapat membantu mengurang kadar glukosa darah menjadi lebih baik untuk mencegah timbulnya komplikasi pada Diabetes Mellitus. Desain yang digunakan dalam penelitian ini adalah Pre ekperimental designdengan rancangan atau desain one group pra test-post test desain (pra pasca dalamsatu kelompok). Populasi semua pasien diabetes mellitus tipe 2 di Desa Masbagek Utara Wilayah Kerja puskesmas Masbagek Lombok Timur sebanyak 25 orang. Sampel dengan teknik sampel jenuh (total sampling). Instrumen yang digunakan yaitu wawancara dan observasi. observasi menggunakan Form Food Recall 24 jam. Analisa data pada penelitian ini menggunakan uji statistik t-test dengan taraf signifikan $0,05 \%$. Berdasarkan hasil perthitungan dengan menggunakan analisa t-tes dengan menggunakan pre-post test one group design dapat diperoleh t-hitung 6 dengan jumlah responden 25 orang diperoleh $\mathrm{DF}=\mathrm{N}-1=24$. Derajat kebebasan bernilai 24 pada t-tabel dengan taraf signifikasi 0,05 bernilai 2,064 sehingga t-hitung>t-tabel $(6>2,064)$ hal ini menunjukan ada pengaruh pendidikan kesehatan keluarga (penyuluhan) terhadap tingkat kepatuhan diet yang lebih tinggi pada responden setelah mengikuti pendidikan kesehatan keluarga (penyuluhan) dibandingkan dengan sebelum diberikan pendidikan kesehatan keluarga (penyuluhan) di Desa Masbagik Utara di Wilayah 
Kerja Puskesmas Masbagik Lombok Timur. Ada pengaruh pendidikan kesehatan keluarga (penyuluhan) terhadap kepatuhan diet pada penderita diabetes mellitus tipe 2 dimana nilai $t$ hitung $>t$ tabel $=6>2,064$. Dengan pemberian pendidikan kesehatan keluarga (penyuluhan) dapat dijadikan sebagai masukan pengetahuan tentang diet pada penderita diabetes mellitus tipe 2 sesuai anjuran diet.

This is an open access article under the Lisensi Creative Commons Atribusi-BerbagiSerupa 4.0 Internasional

Corresponding Author:

Nurul Ilmi

Prodi S1 Keperawatan Sekolah Tinggi Ilmu

Kesehatan (STIKES) Mataram

Email: nurulilmisukses@gmail.com

\section{PENDAHULUAN}

Diabetes melitus adalah kumpulan gejala yang ditimbulkan pada seseorang yang mengalami peningkatan kadar gula (glukosa) darah akibat kekurangan hormon insulin (Almatsier, 2005). Organisasi Internasional Diabetes Federation (IDF) memperkirakan 463 Juta orang pada usia 20 79 tahun didunia menderita Diabetes Militus pada tahun 2019. IDF juga memperoyeksikan jumlah penderita Diabetes Militus pada 10 Negara dengan jumlah pederita tertinggi Cina, India, Amerika Serikat dan Indonesia menempati urutan ke-7 diantara 10 Negara dengan jumlah penderita sebesar 10,7 Juta. Hasil Riskesdas 2018 menunjukkan bahwa prevalensi Diabetes Militus pada usia $\geq 15$ tahun di seluruh Provinsi menunjukkan peningkatan dari 1,5\% pada tahun 2013 menjadi $2 \%$ pada tahun 2018. Dan di NTB sendiri menunjukkan adanya peningkatan dari 0,9\% pada tahun 2013 menjadi $1,6 \%$. Sedangkan di kabupaten Lombok Timur sendiri menempatai urutan pertama dari semua kabupaten di NTB, dengan jumlah pasien terkena penyakit DM sekitar 493 jiwa pada tahun 2012-2013. Dan tahun 2018 Jumlah penderita Diabetes Melitrus (DM) di Kabupaten Lombok Timur menurut data Dinas Kesehatan Lombok Timur tercatat sejumlah 6.484 jiwa. Dari jumlah pasien yang terkena DM di kabupaten Lombok Timur, kecamatan Masbagik menempati urutan keempat dengan jumlah pasien yang terkena diabetes mellitus di Puskesmas Masbagek pada tahun 2013 sekitar 134 jiwa dan pada tahun 2018 terdapat 321 jiwa yang tersebar di beberapa Desa di Kecamatan Masbagik. Berdasarkan study pendahuluan yang dilakukan di 12 Wilayah Kerja Puskesmas Masbagik didapatkan masbagek utara menempati urutan pertama dengan jumlah penderita DM tipe II ada 25 orang dalam kurun waktu 2 bulan.

\section{METODE PENELITIAN}

Jenis penelitian yang di gunakan pada penelitian ini adalah pre-experimental designs (Sugiyono, 2014). Dengan rangcangan pra-eksperiment, one group pre-post test design. Dalam penelitian ini yang menjadi populasi adalah Semua keluarga yang salah satu anggota keluarganya menderita Diabetes Mellitus tipe 2 sampel dalam penelitian ini adalah Semua keluarga yang salah satu anggota keluarganya menderita Diabetes Mellitus tipe 2 di Desa Masbagik Utara, yang berjumlah 25 Analisa data pada penelitian ini menggunakan uji statistik t-test dengan taraf signifikan $0,05 \%$. Data primer diambil dari hasil wawancara dengan anggota keluarga dan penderita diabetes mellitus tipe 2 kemudian dilakukan obsrvasi dengan menggunakan form food recall 24 jam. Yang diobservasi adalah kepatuhan dalam diet yaitu jenis makanan, jumlah makanan, dan jadwal makan (3J) dengan pengisian form food recall 1x24 jam. Form food recall 24 jam adalah form food recall $1 \times 24$ jam digunakan untuk mencatat asupan makanan dan waktu makan responden selama 1x24 jam terakhir. form food recall 24 jam dimodifikasi dari (Gibson, 2005) 


\section{HASIL PENELITIAN}

1. Data umum : berdasarkan hasil dokumentasi data umum responden yang terdiri dari usia, pendidikan dan pekerjaan, sebagai berikut :

a. Karaktristik responden berdasarkan jenis kelamin

Tabel 4.1 Distribusi Responden Berdasarkan Jenis Kelamin.

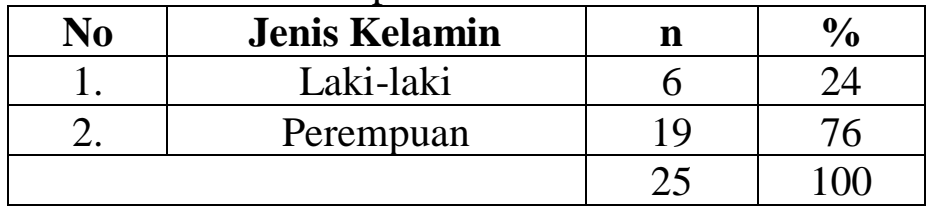

Sumber: Data Sekunder

Dari tabel 4.1 tersebut dapat dilihat bahwa 6responden (24\%) berjenis kelamin laki-laki dan 19 responden (76\%) berjenis kelamin perempuan.

b. Usia Responden

Tabel 4.2 Distribusi Responden Berdasarkan Umur.

\begin{tabular}{|c|c|c|c|}
\hline No & Umur & $\mathbf{N}$ & \% \\
\hline 1. & $30-45$ & 11 & 44 \\
\hline 2. & $46-55$ & 8 & 32 \\
\hline 3. & $56-80$ & 6 & 24 \\
\hline Jumlah & & 25 & 100 \\
\hline
\end{tabular}

Sumber: Data Sekunder yang diolah

Dari tabel 4.2 tersebut dapat diketahui bahwa umur responden paling banyak adalah pada kategori umur 30-45 tahun yaitu sebanyak 11 orang (44\%).

c. Pekerjaan Responden

Tabel 4.4 Distribusi Responden Berdasarkan Pekerjaan.

\begin{tabular}{|c|l|c|c|}
\hline No & Pekerjaan & N & \% \\
\hline 1 & Petani & 6 & 24 \\
\hline 2 & PNS & 2 & 8 \\
\hline 3 & Wiraswasta & 17 & 68 \\
\hline Jumlah & & 25 & 100 \\
\hline
\end{tabular}

Sumber: Data Primer yang diolah

Dari tabel 4.4 tersebut dapat dilihat bahwa sebagian besar responden mempunyai pekerjaan sebagai Petani yaitu sebanyak 6 orang (24\%), PNS 2 orang (8\%), Wiraswasta 17 orang (68\%).

2. Data Khusus

Dalam analisi ini menggunakan pra-eksperiment, one group pre-post test desig dengan langkahlangkah sebagai berikut:

a. Kepatuhan diet pada penderita diabetes mellitus tipe 2 sebelum diberikan pendidikan kesehatan keluarga (penyuluhan).

Tabel 4.6: Distribusi frekuensi responden berdasarkan sebelum diberikan pendidikan kesehatan keluarga (penyuluhan)

\begin{tabular}{|l|c|c|}
\hline Tingkat kepatuhan diet & Frekuensi & Persentase (\%) \\
\hline Patuh & 6 & 24 \\
\hline Tidak patuh & 19 & 76 \\
\hline Jumlah & 25 & 100 \\
\hline
\end{tabular}

Sumber: Data primer yang diolah 
Dari tabel 4.6 dapat diketahui bahwa kepatuhan diet yang dilakukan paling banyak tidak patuh 19 orang responden $(76 \%)$

b. Kepatuhan diet pada penderita diabetes mellitus tipe 2 sesudah diberikan pendidikan kesehatan keluarga (penyuluhan).

Tabel 4.7 Distribusi frekuensi subyek penelitian berdasarkan kepatuhan diet sesudah diberikan pendidikan kesehatan kelurga (penyuluhan)

\begin{tabular}{|c|c|c|}
\hline Kepatuhan diet & Frekuensi & Persentase \\
\hline Patuh & 21 & 84 \\
\hline Tidak patuh & 4 & 16 \\
\hline Jumlah & 25 & 100 \\
\hline
\end{tabular}

Sumber: Data yang diolah

Dari tabel 4.7 dapat diketahui bahwa kepatuhan diet yang dilakukan oleh subyek penelitian sesudah diberikan pendidikan kesehatan keluarga (penyuluhan) adalah subyek penelitian yang tidak patuh menjadi patuh sebanyak 21 orang (84\%).

Tabel 4.9 hasil uji t sebelum dan sesudah pemberian pendidikan kesehatan keluarga (penyuluhan) terhadap kepatuhan diet pada penderita diabetes mellitus tipe 2

\begin{tabular}{|l|l|l|l|l|l|l|l|}
\hline No & $\begin{array}{c}\text { Mean pre- } \\
\text { test }\end{array}$ & $\begin{array}{c}\text { Mean } \\
\text { post-test }\end{array}$ & $\begin{array}{c}\text { Beda rata- } \\
\text { rata }\end{array}$ & P & t-hitung & $\begin{array}{c}\text { t- } \\
\text { tabel }\end{array}$ & Interpretasi \\
\hline 1 & 1,24 & 1,84 & 0,6 & 0,05 & 6 & 2,064 & $\begin{array}{l}\text { t-hitung lebih dari t } \\
\text {-tabel }(6>2,064) \\
\text { Ho ditolak dan Ha } \\
\text { diterima }\end{array}$ \\
\hline
\end{tabular}

Sumber: Data primer yang diolah

Berdasarkan hasil perhitungan menggunakan uji t pada pemberian pendidikan kesehatan keluarga (penyuluhan) sebelum dan sesudah diberikan pendidikan kesehatan keluarga (penyuluhan) diperoleh hasil $t$ hitung sebesar 6 dengan $d b=24$ diperoleh $t$ tabel sebesar 2,064 atau t hitung lebih besear dari t tabel $(6>2,064)$

\section{PEMBAHASAN}

Berdasarkan tabel 4.7 terlihat bahwa 19 responden penelitian tidak patuh dalam melakukan diet sesuai anjuran yaitu (jenis makanan, jumlah makanan, dan jadwal makan) 3J, Hal ini karena responden yang tidak patuh terhadap anjuran diet disebabkan oleh beberapa faktor diantaranya, meningkatnya umur responden menyebabakan terjadinya penurunan daya ingat (lupa). Hal tersebut merupakan ketidak mampuan mengenal atau mengingat sesuatau yang pernah dipelajari atau dialami. (syah M, 2002). Pendapat beberapa ahli menyatakan bahwa dengan meningkatnya umur maka intoleransi glukosa juga mengalami peningkatan. (Asdie, 2000). Tingkat pendidikan responden yang mempengaruhi pola pikir responden terhadap pentingnya diet sesuai anjuran bagi kesehatan.

Setelah Pemberian pendidikan kesehatan (penyuluhan) terkait diet yang dianjurkan pada penderita DM didapatkan hasil seperti yang tercantum pada tabel 4.8 dimana terdapat $84 \%$ responden yang patuh dalam melakukan diet. Hal ini menunjukkan bahwa terjadi perubahan tingkat kepatuhan responden terhadap diet yang dianjurkan setelah diberikan pendidikan kesehatan keluarga (penyuluhan). Diet merupakan salah satu kunci keberhasilan dalam penatalaksanaan penyakit diabetes mellitus tipe 2 . Hal terebut dikarenkan perencenaan makan merupakan salah satu dari 4 pilar utama dalam pengelolaan diabetes mellitus tipe 2 (perkeni, 2011).

Berdasarkan hasil perthitungan dengan menggunakan analisa t-tes dengan menggunakan pre-post test one group design dapat diperoleh t-hitung 6 dengan jumlah responden 25 orang diperoleh $\mathrm{DF}=\mathrm{N}-1=24$. Derajat kebebasan bernilai 24 pada t-tabel dengan taraf signifikasi 0,05 
bernilai 2,064 sehingga t-hitung>t-tabel $(6>2,064)$ hal ini menunjukan ada pengaruh pendidikan kesehatan keluarga (penyuluhan) terhadap tingkat kepatuhan diet pada responden setelah mengikuti pendidikan kesehatan keluarga (penyuluhan) dibandingkan dengan sebelum diberikan pendidikan kesehatan keluarga (penyuluhan)

\section{KESIMPULAN}

Kepatuhan diet sebelum diberikan pendidikan kesehatan keluarga (penyuluhan) pada penderita diabetes mellitus tipe 2 diperoleh hasil 74\% responden tidak patuh dalam melakukan diet yang sesuai anjuran dan sesudah diberikan pendidikan kesehatan keluarga (penyuluhan) diperoleh hasil penelitian yang patuh sebesar $84 \%$.

Berdasarkan hasil uji statistik $t$-test didapatkan hasil $\mathrm{t}$ hitung $>\mathrm{t}$ tabel $(6>2,064)$ maka Ha diterima. hal ini menunjukan ada pengaruh pendidikan kesehatan keluarga (penyuluhan) terhadap tingkat kepatuhan diet sebelum diberikan pendidikan kesehatan keluarga (penyuluhan)

\section{DAFTAR PUSTAKA}

Arikunto, s. 2006. Prosedur Penelitian Status Pendekatan Praktik. Edisi Revisi VI. Cet 13. Jakarta: Rineka Cipta

Basuki, E. 2009. Teknik Penyuluhan Diabetes Mellitus Dalam Penatalaksanaan Diabetes Mellitus Terpadu. Edisi 2. Jakarta: Balai Penerbit FKUJI

Brunner \& suddarth. 2002. Keperawatan Medikal Bedah. Jakarta: Edisi 8. Vol I. Hendro, M 2010. Pengaruh Psikososial Terhadap Pola Makan Penderita Diabetes Mellitus di

Rumah Sakit Umum Daerah Kabupaten Deli Serdang Tahun 2009. Tesis FKM Universitas Sumatra Utara. Medan. Diakses Pada 26 Januari 2013 dari http://scholar.google.co.id

klienfield,N.R. 2006. "Living at an Epicenter of Diabetes Mellitus and Despair”. The New York

Ties. Diakses pada 5 Januari 2012 dari http://www.nytimes.com

Maulana, M. 2008. Mengenal Diabetes Mellitus. Yogyakarta: AR-Ruzz Media. B First.

Notoatmodjo, S. 2002. Metodologi Penelitian Kesehatan Edisi ke-2. Jakarta: PT. Risneka Cipta.

Notoatmojo, S. 2003. Pendidikan Kesehatan dan Perilaku. Jakarta: Rineka Cipta

Notoatmodjo, S. 2010. Ilmu Perilaku Kesehatan. Jakarta: Rineka Cipta

Nursalam. 2003. Konsep Dan Penerapan Metodologi Penelitian Ilmu Keperawatan. Jakarta: Salemba Medika.

Nursalam. 2008. Pendidikan Dalam Keperawatan.Jakarta: Salemba Medika

Perkeni (Perkumpulan Endokrinologi Indonesia). 2011. Konsumsi Pengelolaan dan Pencegahan Diabetes Mellitus Tipe 2 di Indonesia Tahun 2011.

Sarwono, 2004. Sosiologi Kesehatan. Jakarta: Rafika Aditama

Setiadi, 2007. Konsep \& Penulisan Riset Keperawatan. Surabaya: Akper Hang Tuah.

Setiadi. 2008. Konsep dan Proses Keperawatan Keluarga. Edisi Pertama. Yogyakarta: Graha Ilmu

Sugiyono, 2006. Metode Penelitian Kuantitatif, Kualitatif: Alfabeta Bandung.

Sugiyono, 2010. Statistik Untuk Penelitian. Cet ke-16. Bandung: Alfabeta

Sutanto teguh, 2013. Diabetes deteksi, pencegahan, pengobatan. Cet ke-1. Yogyakarta: Buku

Pintar Vitahealth. 2006. Diabetes. Cet ke-4. Jakarta: PT Gramedia Pustaka Utama

https://www.kemkes.go.id/resources/download/profil/PROFIL_KAB_KOTA_2018/5203_NTB_Ka

b_Lombok_Timur_2018.pdf

https://pusdatin.kemkes.go.id/resources/download/pusdatin/infodatin/Infodatin-2020-DiabetesMelitus.pdf 